\title{
Effect of Nickel Powder Buffering Layer on Microstructure and Hardness Properties of High Carbon Steel / Stainless Steel Arc Stud Welding
}

\author{
Muhaed Alali ${ }^{*}$ (D), Mohammed H. Abass ${ }^{b}$,Waseem S. Abbas ${ }^{c}$, Abeer A. Shehab $^{d}$ (D) \\ ${ }^{a}$ University of Kufa, Faculty of Engineering, Department of Materials Engineering, 54001 Najaf, Iraq \\ ${ }^{b}$ Ministry of Oil, Midland oil Company, Department of Mechanical Engineering, Baghdad, Iraq \\ 'Al-Furat Al-Awsat Technical University, Babylon Technical Institute, 51009 Babylon, Iraq \\ ${ }^{d}$ University of Diyala, Faculty of Engineering, Department of Materials Engineering, Diyala, Iraq
}

Received: October 14, 2019; Revised: December 8, 2019; Accepted: February 29, 2020

In this study, arc stud welding process was employed for welding AISI 316 stainless steel studs to AISI 1060 high carbon steel plates. A disc of Ni powder prepared and used as a buffering layer to enhance the properties of welding area. Optical and scanning electron microscopy were used to examine the microstructure. Energy-Dispersive X-ray (EDX) and X-Ray Diffraction (XRD) tests were performed to analyse and identify elements and phases, respectively in the weld region. The results observed that Ni powder prevented the direct contact between the dissimilar base metals. Existing of $\mathrm{Ni}$ altered the microstructure of the weld zone and encouraged dendritic type over cellular. Hardness reduced in the weld region from $600 \mathrm{HV}$ to $200 \mathrm{HV}$ due to the effect of Ni powder which prevented the formation of brittle $\mathrm{Fe}-\mathrm{Cr}$ phase.

Keywords: Arc stud welding, AISI 316 stainless steel, AISI 1060 carbon steel, dissimilar welding, microstructure, hardness, $\mathrm{Fe}$-Cr phase.

\section{Introduction}

In a process system that contains multiple parts, every part might work at a specific condition. Consequently, combination of different materials is necessary in design, especially in applications that require a certain combination of properties ${ }^{1,2}$. Welding technique can be employed to join between dissimilar metals. The properties of the resultant weld are governed by base metal (BM), filler metal, microstructural development in fusion zone (FZ) and type of implemented welding process ${ }^{3}$.

Many factors should be considered during dissimilar welding such as physical and mechanical properties of $\mathrm{BM}$ and possibility of alloying and compounds in the FZ. However, the employed welding technique might be the most effective factor. Based on literature, fusion and solid-state welding techniques have been used in joining between dissimilar metals ${ }^{4-7}$.

Welding carbon steel to stainless steel has a wide application in nuclear power plant, oil and petrochemical industries in components such as pressure vessels, heat exchanger and boilers. However, high carbon steel have poor weldability due to the high carbon content, which raises the hardenability and causes reduction in ductility and toughness ${ }^{8,9}$. Other issues included in fusion welding of high carbon steel are migration of carbon and possibility of formation of hard and brittle martensite phase in the heat affected zone (HAZ) $)^{10,11}$.

Conventional fusion welding processes such as shielded metal arc welding and gas metal arc welding techniques,

*e-mail: mowahid.alali@uokufa.edu.iq are not feasible for joining many dissimilar metals due to metallurgical problems during welding, e.g. formation of intermetallic compounds and solidification cracking that lead to failure of the welded part during service ${ }^{12,13}$. Arc stud welding (ASW), which specialises in welding studs to plates is characterised with localised heating capability and performing welding in very short time ${ }^{14-16}$. Therefore, when ASW process is used for welding high carbon steel, the carbon diffusion might be restricted, and a very small HAZ can be produced. This offers a possibility to overcome the carbide formation in $\mathrm{FZ}$ and control martensitic transformation issue in $\mathrm{HAZ}^{17}$.

Another method that is used to improve the weldability of high carbon steel and increase the feasibility of joining high carbon steel to stainless steel is using of buffering layer. This can be accomplished by deposition a layer of an alloy, such as Ni base alloy onto the weld area before welding ${ }^{2,11}$. The deposition of $\mathrm{Ni}$ base alloy can significantly reduce the carbon migration and mitigate change in chemical, physical and mechanical properties throughout the weld ${ }^{10,18}$. Moreover, $\mathrm{Ni}$ has an intermediate thermal expansion coefficient that lays between carbon steel and austenitic stainless steel, Table 1, thereby decreases thermal stresses across the weld interface and consequently reduces internal tension stresses and improves life of the dissimilar joint ${ }^{19}$.

In gas power plants, the exhausts are usually made of high carbon steel and welded with stainless steel studs using shielded metal arc welding (SMAW) process. The high heat input of SMAW could affect negatively on the joint properties. Therefore, in this research, ASW process was performed instead of conventional arc welding process, and the impact 
of Ni powder buffering layer on the microstructure and hardness properties of the dissimilar joint was investigated.

\section{Experimental Procedure}

In this investigation, full threaded (M12 mm, $80 \mathrm{~mm}$ length) studs of AISI 316 stainless steel and plates of AISI 1060 carbon steel with dimensions of $5 \times 5 \times 8 \mathrm{~mm}$ were used as a $\mathrm{BM}$. The carbon steel plates received in as-rolled condition. Commercially pure Ni powder with particle size of $50 \mu \mathrm{m}$ was used for making the buffering layer. Table 2 shows the chemical composition of the materials used in this study. Ni powder was used as a buffering layer in a shape of disc with dimensions of $12 \mathrm{~mm}$ diameter and $1 \mathrm{~mm}$ thickness. The disc-shape was produced by compressing the Ni powder with 10-ton press in a suitable die. Prior welding, the disc placed in a solid hole with $12 \mathrm{~mm}$ diameter and $1 \mathrm{~mm}$ depth made in the centre of carbon steel plate. A schematic diagram of weld assembly presented in Figure 1.

ASW process was used to perform the joint between studs and plates using DABOTK (1000) welding machine. Welding parameters utilised in this study were 600A and $800 \mathrm{~A}$ welding current and $0.2 \mathrm{~s}, 0.3 \mathrm{~s}$ and $0.4 \mathrm{~s}$ welding time. Carbon steel plates were annealed by heating to about $850^{\circ} \mathrm{C}$, holding for $20 \mathrm{~min}$ and left to cool in furnace. Before welding, the carbon steel plates were preheated at $350^{\circ} \mathrm{C}$ to prevent the heat sink during welding. The weldments then cut and prepared for metallographic examination and microhardness test using electrical discharge machining (EDM) technique following by standard grinding and polishing methods.

Microstructure was examined by optical microscope. To reveal microstructures at better details, the samples were etched with fresh mixed acids (two parts of acetic acid, two parts of $\mathrm{HNO}_{3}$ and three parts of HCL) at stainless steel side and Nital solution at carbon steel side. The elemental distribution was studied by EDX analysis using Inspect F device. The scan performed in secondary electron mode with accelerating voltage of $20 \mathrm{kV}$ and spot size of 5. XRD test was carried out to identify phases and compounds. SHMADZU diffractometer model XRD 6000, Japan was used to perform the XRD scan. Vickers microhardness test was conducted according to ASTM 384 standard using LARYEE microhardness testing device. The measurements were engaged along the BM, HAZ and FZ, using 500g load and $15 \mathrm{~s}$ dwell time.

\section{Results and Discussion}

\subsection{Macrostructure and microstructure examination}

Welding samples were subjected to visual test according to ISO 14555 to evaluate welding parameters with respect to weld appearance. The Welds should be free of welding defects such as lack of fusion and undercut. Only passed samples (Table 3) were subjected to further microstructure and hardness tests.

Figure 2 shows the macrostructure of weldments prepared at different welding conditions. Apparently, the structure consists of three regions. The top region represents the stud, the fusion zone (FZ) is located in the middle and the region at the bottom is the carbon steel plate. An increment in the thickness of FZ can be noticed when Ni powder was added. Existing and distribution of Ni through the FZ was detected and confirmed by EDX analysis as shown in Figure 3 and Table 4. Ni wt $\%$ increase towards the centre of the $\mathrm{FZ}$ as shown in spectrum 20 and 21 in Figure 3 resulting from $\mathrm{Ni}$ powder addition. The increment of $\mathrm{Ni}$ wt $\%$ in $\mathrm{FZ}$ played an important role in controlling microstructure and mechanical properties.

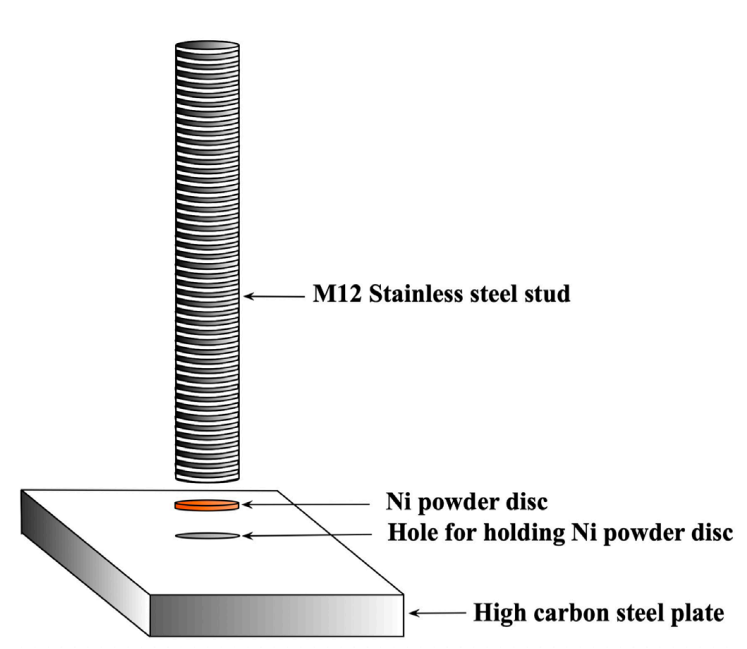

Figure 1. Schematic illustration of the ASW assembly.

Table 1. Physical properties of AISI 316 stainless steel and AISI 1060 carbon steel ${ }^{20}$.

\begin{tabular}{cccc}
\hline Material & $\begin{array}{c}\text { Melting temperature } \\
\left({ }^{\circ} \mathrm{C}\right)\end{array}$ & $\begin{array}{c}\text { Thermal conductivity } \\
(\mathrm{W} / \mathrm{m} . \mathrm{K})\end{array}$ & $\begin{array}{c}\text { Thermal expansion coefficient } \\
\left(10^{-6}\left({ }^{\circ} \mathrm{C}\right)^{-1}\right)\end{array}$ \\
\hline AISI 316 & 1400 & 16.3 & 15.9 \\
\hline AISI 1060 & 1510 & 49.8 & 11.3 \\
\hline $\mathrm{Ni}$ & 1455 & 90.0 & 13 \\
\hline
\end{tabular}

Table 2. Chemical composition of the materials used in this study.

\begin{tabular}{|c|c|c|c|c|c|c|c|c|c|c|}
\hline \multirow{2}{*}{ Base metal } & \multicolumn{10}{|c|}{ Alloying elements (wt.\%) } \\
\hline & $\mathrm{C}$ & $\mathrm{Si}$ & $\mathrm{Mn}$ & $\mathrm{P}$ & $\mathrm{S}$ & $\mathrm{Cr}$ & $\mathrm{Ca}$ & $\mathrm{Ni}$ & Mo & $\mathrm{Fe}$ \\
\hline AISI 316L & 0.03 & 0.3 & 1.54 & 0.03 & 0.01 & 16.5 & - & 12 & 2.04 & Bal. \\
\hline AISI 1060 & 0.62 & 0.26 & 0.83 & 0.02 & 0.02 & 0.85 & - & - & - & Bal. \\
\hline $\mathrm{Ni}$ & 0.01 & - & - & - & 0.001 & - & 0.0013 & 99.5 & - & 0.013 \\
\hline
\end{tabular}


Table 3. Welding parameters and conditions used in this research

\begin{tabular}{cccc}
\hline \multicolumn{2}{c}{ Welding parameters } & \multirow{2}{*}{ Addition of Ni disk } & Comments \\
\hline Current $(\mathrm{A})$ & Time $(\mathrm{s})$ & & Short welding time (low heat input) causes immediate weld failure \\
\hline 600 & 0.2 & No & Passed* \\
\hline 600 & 0.3 & Yes & Excessive heat input causes weld defect for without Ni condition \\
\hline 600 & 0.4 & Yes & Passed \\
\hline 800 & 0.2 & Yes & Passed \\
\hline 800 & 0.3 & Yes & Excessive heat input causes weld defect for both conditions \\
\hline 800 & 0.4 & Yes &
\end{tabular}

* Weld passed initial visual test.
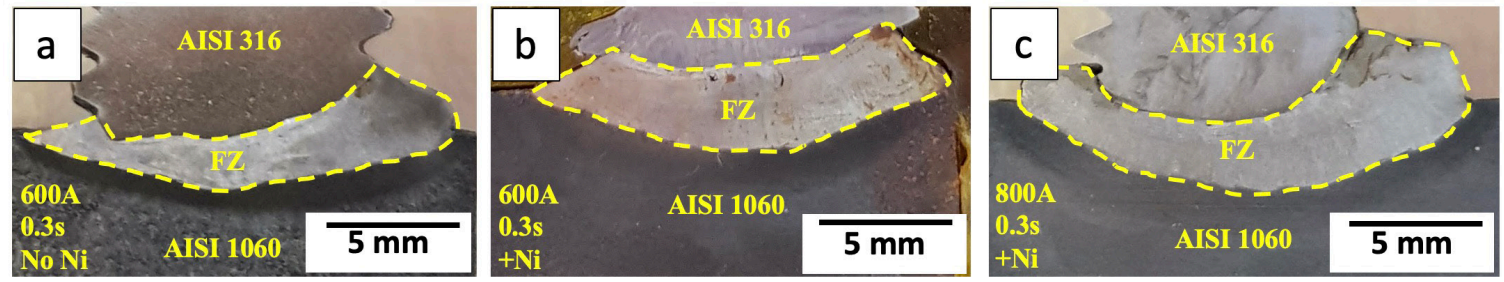

Figure 2. Macrophotography of welds (a) $600 \mathrm{~A}, 0.3 \mathrm{~s}$ and without $\mathrm{Ni}$ (b) $600 \mathrm{~A}, 0.3 \mathrm{~s}$, with $\mathrm{Ni}$ (c) $800 \mathrm{~A}, 0.3 \mathrm{~s}$, with $\mathrm{Ni}$
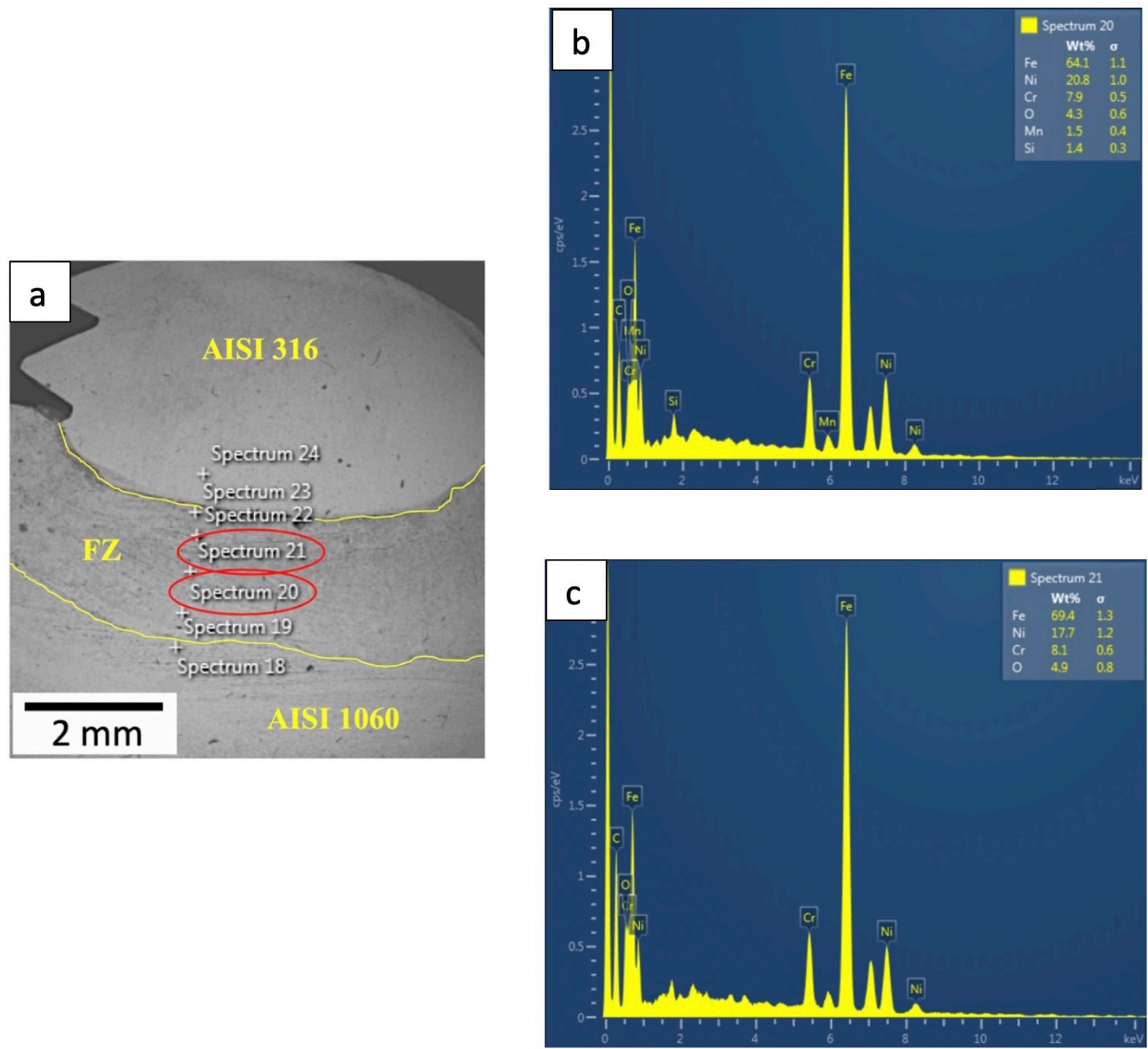

Figure 3. EDX analysis of the weld showing the spectrums location and existing of Ni at the centre of FZ. (a) SEM image representing area of EDX analysis. (b) Spectrum 21 (c) Spectrum 20. 
Microstructure of the welded region adjacent to carbon steel is shown in Figure 4. Lower melting temperature and thermal conductivity of AISI 316 than AISI 1060, Table 1, causes FZ to be completely consisted of re-solidified microstructure of austenitic stainless steel that is characterised with ferrite-austenite (FA) solidification mode with ferrite as primary phase and austenite as a secondary. This solidification mode can be predicted using WRC-1992 constitutional diagram that introduced by welding research council in 1992 (Figure 5), which depends on $\mathrm{Cr}$ and $\mathrm{Ni}$ equivalents of the steel. At the region near fusion boundary for the all welding conditions, dendritic structure consists of skeletal columnar ferrite in austenite matrix (Figure 6) was mainly observed. It is believed that the dendritic mode of solidified structure is resulted from high speed, localised heat of ASW process and existing of relatively high thermal conductive Ni powder (Table 1). All these factors led to decrease the $\mathrm{G} / \mathrm{R}$ ratio, where, $\mathrm{G}$ is thermal gradient and $\mathrm{R}$ is solidification rate and encourage dendritic over cellular structure ${ }^{21,22}$.

Many locations in the welding joints without Ni powder featured with presenting of cellular-type structure as shown in Figure 7. The absence Ni increases the G/R ratio and encouraged cellular structure over dendritic ${ }^{14,23}$. At the weld centerline (Figure 8), columnar dendritic structure continued dominating at all weld conditions However, at $800 \mathrm{~A}$, the grains showed a noticeable growth and larger spacing between dendrites as presented in Figure 8c. The grain growth could be due to the relatively higher heat input of this condition. At the region adjacent to stainless steel, skeletal ferrite was mainly observed for the different welding conditions as shown in Figure 9. The columnar dendritic structure formed due to the high solidification rate that overcomes thermal gradient in this region due to the high speed and localised heat of ASW process.

Table 4. Weight percentage of $\mathrm{Fe}, \mathrm{Ni}$ and $\mathrm{Cr}$ of the spectrums in Figure 3a.

\begin{tabular}{ccccc}
\hline Spectrum No. & Fe Wt.\% & Ni Wt.\% & Cr Wt.\% & Comment \\
\hline 18 & 100 & - & - & No Ni \\
\hline 19 & 96 & - & - & No Ni \\
\hline 20 & 64.1 & 20.8 & 8.9 & Ni rich region \\
\hline 21 & 69.4 & 17.7 & 8.2 & Ni rich region \\
\hline 22 & 69.8 & 17.4 & 8.1 & Ni rich region \\
\hline 23 & 67.7 & 17.5 & 18.1 & Ni rich region \\
\hline 24 & 64.5 & 13.1 & & lower Ni $\%$ \\
\hline
\end{tabular}
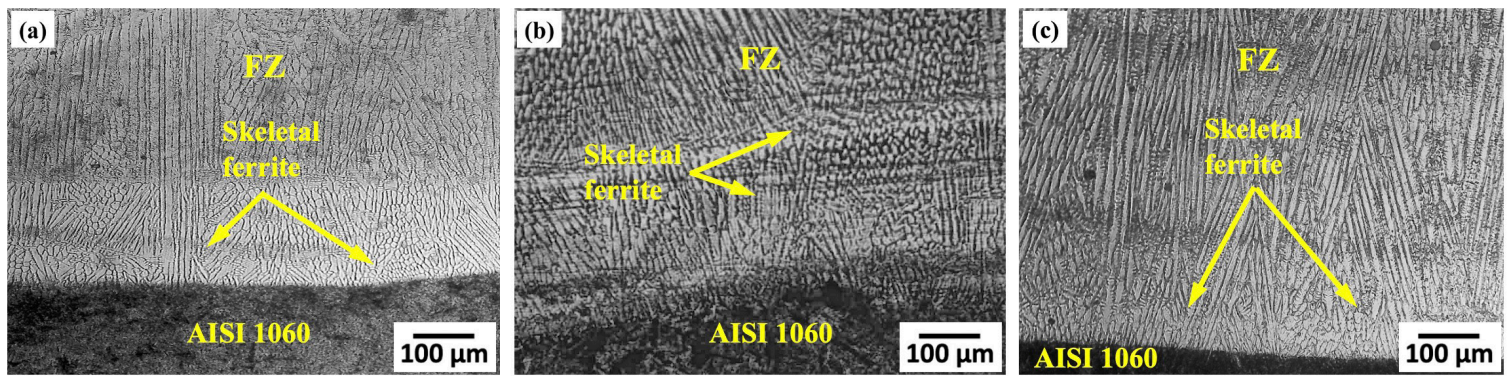

Figure 4. Microphotography of areas adjacent to fusion boundary at carbon steel side with different welding conditions (a) $600 \mathrm{~A}, 0.3 \mathrm{~s}$, no Ni (b) 600A, 0.3s, with Ni (c) $800 \mathrm{~A}, 0.3 \mathrm{~s}$, with Ni.

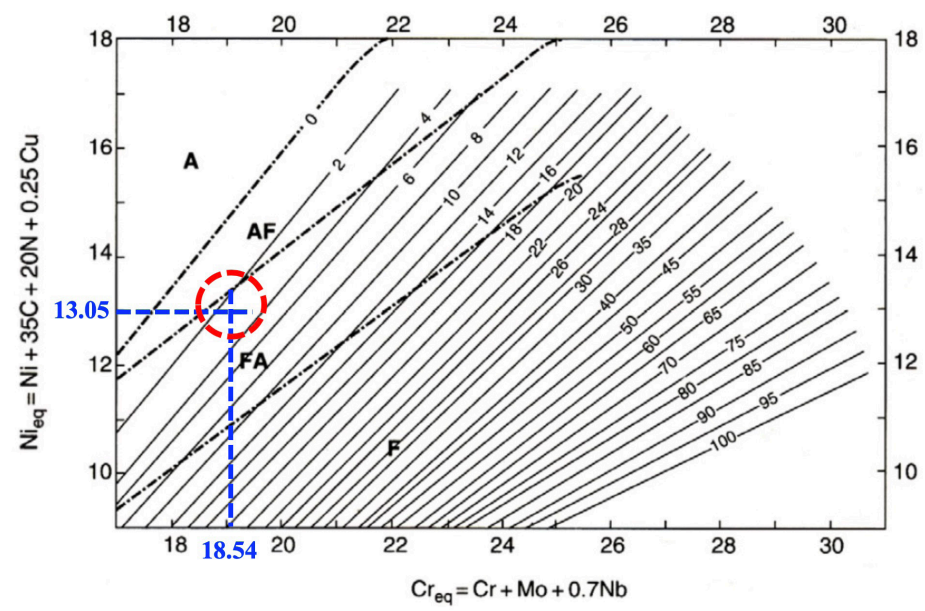

Figure 5. WRC-1992 constitutional diagram. Adapted from ${ }^{14}$. 


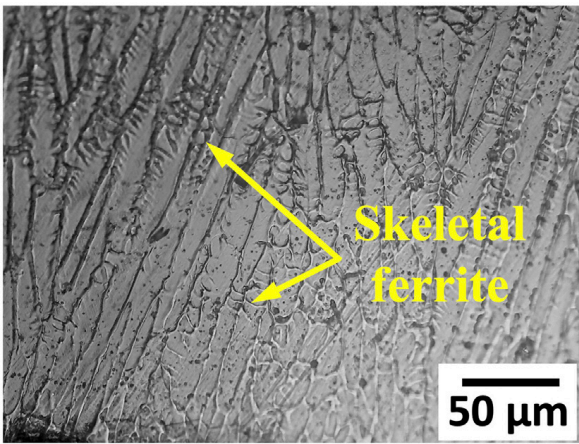

Figure 6. Skeletal ferrite microstructure in the FZ at higher magnification.

\subsection{Hardness test}

Figure 10 shows distribution of hardness reading across the weld, covering BM, HAZ and FZ of the weld conditions (600 A and $0.3 \mathrm{~s}$, with and without Ni powder). At carbon steel side, significant increase in hardness at HAZ was obtained with more than $750 \mathrm{HV}$. The high hardness number can be explained in terms of the effect of high carbon content that increases hardenability and consequently susceptibility of carbon steel to cooling rate or on the other word, welding speed. In FZ, the effect of Ni powder was clearly observed. Hardness of the weld without Ni powder reached to $600 \mathrm{HV}$. While with Ni addition, hardness decreased to $200 \mathrm{HV}$. Formation of brittle Fe-Cr phase, which was detected by XRD in FZ, Figure 11, could be the main reason for

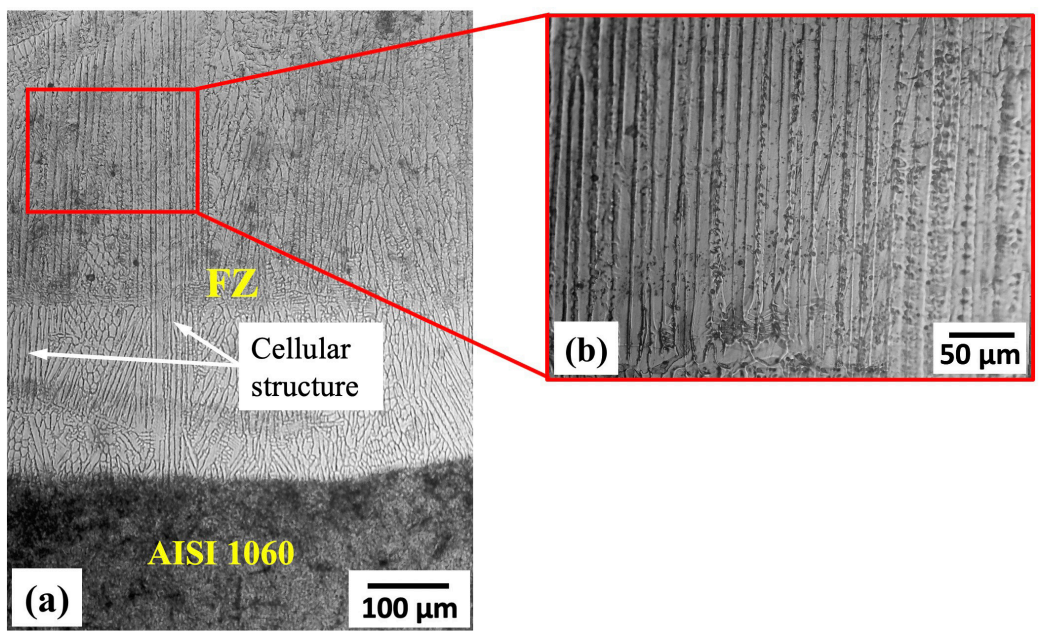

Figure 7. (a) Cellular microstructure at different regions in weldment of $600 \mathrm{~A}, 0.3 \mathrm{~s}$, no Ni conditions (b) Cellular structure at higher magnification.
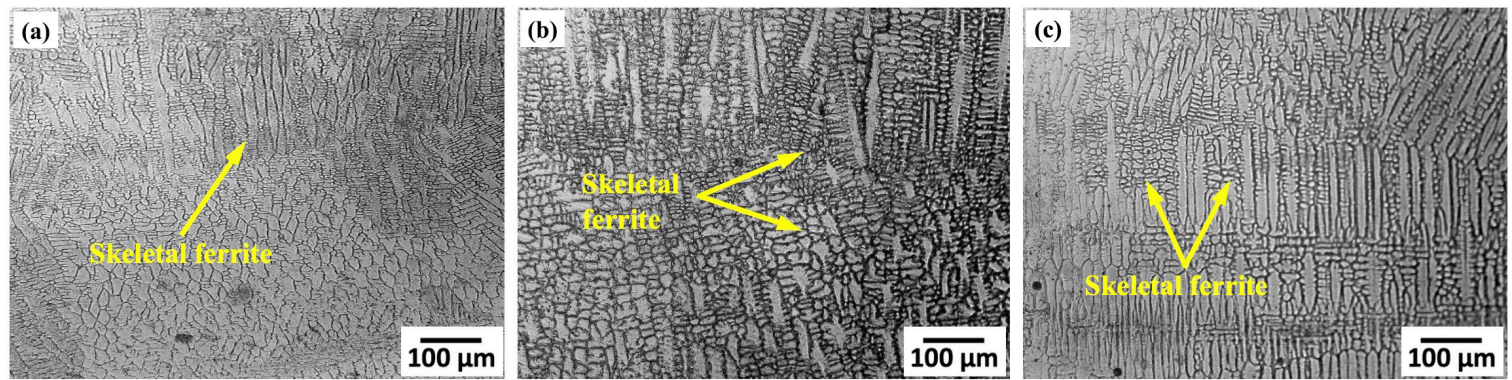

Figure 8. Microphotography of areas at the weld centreline with different welding conditions (a) $600 \mathrm{~A}, 0.3 \mathrm{~s}$, no Ni (b) $600 \mathrm{~A}, 0.3 \mathrm{~s}$, with $\mathrm{Ni}(\mathrm{c}) 800 \mathrm{~A}, 0.3 \mathrm{~s}$, with Ni.
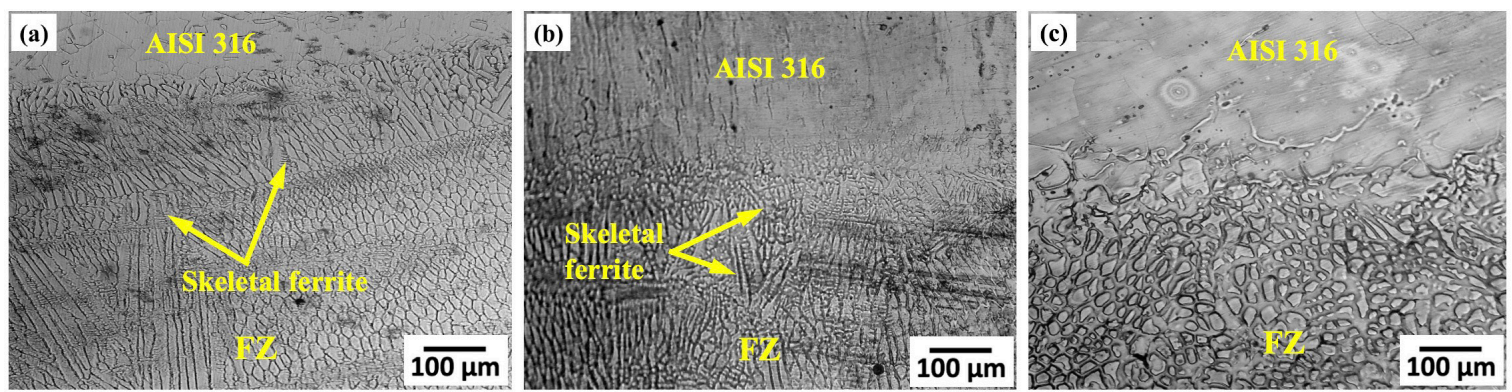

Figure 9. Microphotography of areas adjacent to fusion boundary at stainless steel side with different welding conditions (a) $600 \mathrm{~A}, 0.3 \mathrm{~s}$, no $\mathrm{Ni}$ (b) 600A, 0.3s, with $\mathrm{Ni}(\mathrm{c}) 800 \mathrm{~A}, 0.3 \mathrm{~s}$, with $\mathrm{Ni}$ 


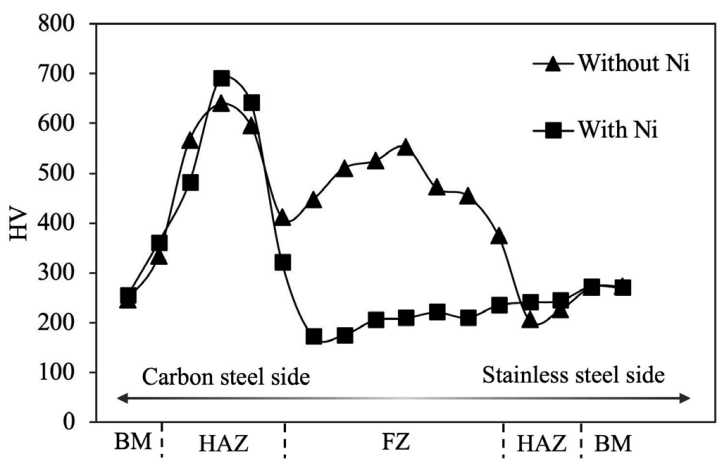

Figure 10. Hardness measurements across BM, HAZ, and FZ of the dissimilar joint.

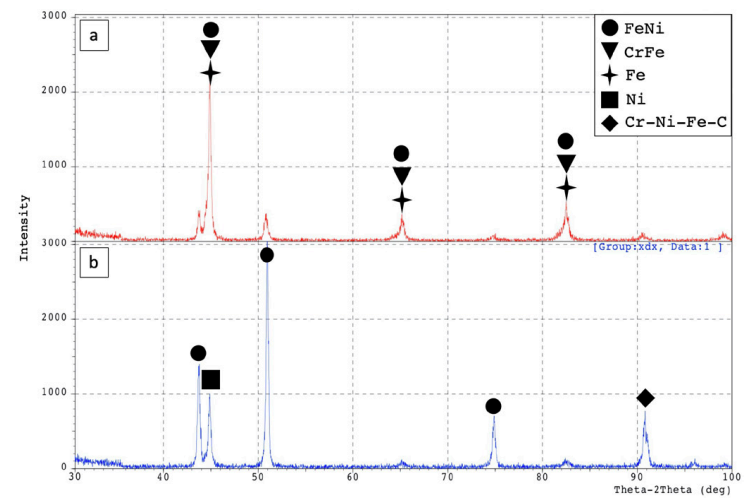

Figure 11. XRD of welds (a) without Ni powder (b) with Ni powder.

increasing hardness inside the weld area ${ }^{14,24}$. The addition of $\mathrm{Ni}$ powder raised $\mathrm{Ni}$ content and reduced $\mathrm{Fe}$ and $\mathrm{Cr}$ and therefore avoided formation of $\mathrm{Fe}-\mathrm{Cr}$.

\section{Conclusions}

In the present work AISI 316 stainless steel studs were welded to AISI 1060 high carbon by ASW process. Ni powder disc was utilised as a buffering layer. The following points can be concluded from this study:

- Lower melting temperature and thermal conductivity of AISI 316 than AISI 1060, causes FZ to be completely consisted of re-solidified microstructure of austenitic stainless steel FA solidification mode.

- Many locations in the welding joints without $\mathrm{Ni}$ powder featured with presenting of cellular-type structure.

- Addition of Ni powder affected the microstructure of the FZ by encouraging growth of dendritic solidification type over cellular.

- Hardness significantly reduced in the weld region from $600 \mathrm{HV}$ to $200 \mathrm{HV}$ once Ni powder disc was applied and formation of brittle $\mathrm{Fe}-\mathrm{Cr}$ phase was eliminated.

\section{References}

1. Pouraliakbar H, Hamedi M, Kokabi AH, Nazari AJMR. Designing of CK45 carbon steel and AISI 304 stainless steel dissimilar welds. Mater Res. 2013;17(1):106-14.
2. Rathod DW, Singh P, Pandey S, Aravindan SJMS. Effect of buffer-layered buttering on microstructure and mechanical properties of dissimilar metal weld joints for nuclear plant application. Mater Sci Eng A. 2016;666:100-13.

3. Cox C, Kiser SJWJ. Fusion welding of dissimilar metals for high-temperature strength. Weld J. 1992;71(5):67-70.

4. Gao M, Chen C, Gu Y, Zeng XJM. Microstructure and tensile behavior of laser arc hybrid welded dissimilar $\mathrm{Al}$ and Ti alloys. Materials. 2014;7(3):1590-602.

5. Wu A, Song Z, Nakata K, Liao J, Zhou LJM. Interface and properties of the friction stir welded joints of titanium alloy Ti6A14V with aluminum alloy 6061. Mater Des. 2015;71:85-92.

6. Wang P, Chen X, Pan Q, Madigan B, Long J. Laser welding dissimilar materials of aluminum to steel: an overview. Int $\mathbf{J}$ Adv Manuf Technol. 2016;87(9-12):3081-90.

7. Chen S, Zhang M, Huang J, Cui C, Zhang H, Zhao X. Microstructures and mechanical property of laser butt welding of titanium alloy to stainless steel. Mater Des. 2014;53:504-11.

8. Bahador A, Hamzah E, Mamat MF. Effect of filler metals on the mechanical properties of the dissimilar welding of stainless steel 316L and carbon steel A 516 Gr 70. J Teknol. 2015;75(7):61-5.

9. Chung Y, Fujii H, Ueji R, Tsuji N. Friction stir welding of high carbon steel with excellent toughness and ductility. Scr Mater. 2010;63(2):223-6.

10. Rathod DW, Singh RR, Pandey S, Aravindan S, Singh PJMS. Influence of graded compositions and carbon diffusivities in buttering on structural integrity of dissimilar metal welds. Mater Sci Eng A. 2017;702:289-300.

11. Rathod DW, Pandey S, Aravindan S, Singh PKJAMS. Metallurgical behaviour and carbon diffusion in buttering deposits prepared with and without buffer layers. Acta Metall Sin. 2017;30(2):120-32.

12. Sekhar N, Russell J, McPherson N. Autogenous Nd: YAG laser welding of $6 \mathrm{~mm}$ thick dissimilar steels. In: Proceedings of the Laser Materials Processing Conference and Laser Microfabrication Conference (ICALEO); 2001; Jacksonville, Florida, USA. Orlando: Laser Institute of America; 2001. p. 382-91.

13. Wang T, Zhang B, Wang H, Feng JJJOME. Microstructures and mechanical properties of electron beam-welded titanium-steel joints with vanadium, nickel, copper and silver filler metals. J Mater Eng Perform. 2014;23(4):1498-504.

14. Abbas EN, Omran S, Alali M, Abass MH, Abood AN. Dissimilar welding of AISI 309 stainless steel to AISI 1020 carbon steel using arc stud welding. In: 2018 International Conference on Advanced Science and Engineering (ICOASE); 2018 Nov 29; Duhok, Iraq. New Jersey: IEEE; 2018. p. 462-7.

15. Yilmaz NF, Hamza AAJMT. Effect of process parameters on mechanical and microstructural properties of arc stud welds. Mater Test. 2014;56(10):806-11.

16. Başyiğit AB, Kurt AJM. Investigation of the weld properties of dissimilar s32205 duplex stainless steel with aisi 304 steel joints produced by arc stud welding. Metals. 2017;7(3):77.

17. Ramana PV, Reddy GM, Mohandas T, Gupta AJM. Microstructure and residual stress distribution of similar and dissimilar electron beam welds: maraging steel to medium alloy medium carbon steel. Mater Des. 2010;31(2):749-60.

18. Rathod DW, Pandey S, Singh P, Prasad RJMS. Experimental analysis of dissimilar metal weld joint: ferritic to austenitic stainless steel. Mater Sci Eng A. 2015;639:259-68.

19. ASM International. Properties and selection: nonferrous alloys and special-purpose materials. Materials Park: ASM International; 1990.

20. Race JM. Carbon diffusion across dissimilar steel welds. Cambridge: University of Cambridge; 1992.

21. Tjong S, Zhu S, Ho N, Ku J. Microstructural characteristics and creep rupture behavior of electron beam and laser welded 
AISI 316L stainless steel. J Nucl Mater. 1995;227(1-2):2431.

22. Abass M, Alali M, Abbas W, Shehab A. Study of solidification behaviour and mechanical properties of arc stud welded AISI 316L stainless steel. J Achiev Mater Manuf Eng. 2019;1(97):5-14.
23. Alali M, Todd I, Wynne B. Through-thickness microstructure and mechanical properties of electron beam welded $20 \mathrm{~mm}$ thick AISI 316L austenitic stainless steel. Mater Des. 2017;130:488-500.

24. Hsieh C-C, Wu W. Overview of intermetallic sigma $(\sigma)$ phase precipitation in stainless steels. ISRN Metall. 2012;2012:732471. 